Violence and Victims

\title{
Help-Seeking Behavior Among Moroccan, Romanian, and Ecuadorian Women Experiencing Intimate Partner Violence in Spain
}

\author{
Carmen Vives-Cases, PhD \\ Alicante University, Spain \\ CIBER de Epidemiología y Salud Pública, Madrid, Spain
}

Daniel La Parra,

Alicante University, Spain

This study aims to identify different types of response to intimate partner violence (IPV) and help-related seeking behavior among Spain's most numerous immigrant groupsMoroccans, Romanians, and Ecuadorians. Women reporting physical, sexual and/or psychological violence by a current or former intimate partner $(n=194)$ were selected from a cross-sectional study based on 1,607 surveys (2011). There are $84 \%$ of surveyed battered women who reported seeking help through informal and/or formal channels. The most frequently reported informal help-seeking behavior was talking with the abusive partner (from $63 \%$ to $83 \%$ ). Moroccans identified social services (29.6\%) and health care $(25.9 \%)$ professionals as their most frequently used formal resources when seeking help. Approximately $32 \%$ of Ecuadorians and Romanians declared having reported their partners to the police. Among all of the women, seeking help through formal channels was more probable in cases where the severity of IPV was high (adjusted odds ratio $=5.69$, $95 \%$ confidence interval $[2.29,14.12]$ ). It is needed to increase professionals' opportunities to intervene in cases of IPV before they become severe.

Keywords: intimate partner violence; battered women; immigrant; help-seeking 35

eaving an abusive intimate relationship is such a complex process that it has been termed the critical path, in reference to the multiple barriers women encounter in leaving an abusive relationship. Barriers may exist regarding both informal (e.g., family, friends) and formal (e.g., professionals, institutions, services) resources, and in relations to different inhibitory factors that may influence women's decisions (Sagot, 2005). The critical path can be understood as an iterative process that includes factors related to women and their individual actions as well as the social responses provided by family, friends, professionals, institutions, services, and others (Sagot, 2005). Housing, employment, income, and safety concerns, together with other formal resources, such as the level of effectiveness of counseling, quality of legal or police support, and other 
contextual factors such as intimate partner violence (IPV) prevalence at the national level and/or level of human development have been previously identified as relevant predictors of women's help-seeking behavior through both informal and formal resources (Anderson \& Saunders, 2003; Barnett, 2001; Duterte et al., 2008; Fanslow \& Robinson, 2010; Koepsell, Kernic, \& Holt, 2006; Linos, Slopen, Berkman, Subramanian, \& Kawachi, 2014; Ponic et al., 2011).

It has been estimated that in 58\%-75\% of IPV cases (depending on the country studied), no help is sought from any type of formal resource (Barrett \& St. Pierre, 2011; Djikanović et al., 2012; Jayasuriya, Wijewardena, \& Axemo, 2011; Kiss et al., 2012; Morrison, Luchok, Richter, \& Parra-Medina, 2006; Naved, Azim, Bhuiya, \& Persson, 2006). For many women, the ongoing patterns of abuse and control as well as IPV severity influence their help-seeking behavior (Flicker et al., 2011; Gondolf \& Fisher, 1988). The extent and types of support women receive from their relatives or from professionals are also important factors that influence their decision to seek help (Brabeck \& Guzmán, 2008).

In recent years, a large number of studies on IPV in ethnic minority and immigrant populations have been published, some of which have reported a higher likelihood of IPV and mortality because of IPV among immigrant women compared to nonimmigrant women (Denham et al., 2007; Lown \& Vega, 2001; Raj \& Silverman, 2002; C. Vives-Cases et al., 2008; C. Vives-Cases et al., 2010). However, prevalence rates among immigrant and nonimmigrant women may differ by country and women's characteristics such as country of origin, administrative status, and length of stay in the host country (Du mont et al., 2012).

Barriers to accessing formal IPV sources, such as not being fluent in the host country's language, limited knowledge of available IPV-related services, and/or the lack of access to culturally competent IPV services, may put immigrant women in a socially vulnerable situation (Ahmad, Driver, McNally, \& Stewart, 2009; Brabeck \& Guzmán, 2008; Crandall, Senturia, Sullivan, \& Shiu-Thornton, 2005; Dutton, Orloff, \& Hass, 2000; Hyman, Forte, Du Mont, Romans, \& Cohen, 2006; Ting, 2010). These barriers might interact with other inhibitory factors to seeking help through both formal and informal resources such as shame, stigma and/or fear of the abuser, women's perception of being responsible for keeping family and marital harmony and/or few opportunities to get a decent job or earn an income that would provide a means for financial independence from their partners, as well as fear of losing their children or residence permit (Amanor-Boadu et al., 2012; Hyman et al., 2011; Lee \& Hadeed, 2009). Women's exposure to these barriers may be heightened by abusers' coercive and/or controlling mechanisms related to administrative status in the host countries. (This could include, for example, not filing or withdrawing required documents for granting a woman and her children regular immigration status or threatening to

AQ3 report a woman to officials for deportation if she calls the police) has been recognized by experts as one type of "immigration-related abuse" (Ammar, Couture-Carron, Alvi, \& San Antonio, 2013).

Some countries have attempted to address IPV among immigrant women by developing specific programs and legal tools (Kiss et al., 2012; Shirwadkar, 2004). In Spain, where almost one fourth of partnered immigrant women (23.1\%) experience physical and/or psychological IPV (Vives-Cases et al., 2010), Organic Law 1/2004 states that immigrant women in an IPV situation may request a restraining order, which in turn entitles them to apply for and obtain a residence permit independently of their partner in the case that their original permit was for family reunification, which made them dependent on the aggressor 
for the right to residence. Organic Law 10/2011 of July 27, 2011, extends the rights of immigrant women in an irregular situation, establishing the option to request permission to reside (including their children) and work because of exceptional circumstances once a restraining order has been granted. This permission is not definitively approved until criminal proceedings have concluded. Women can also apply for provisional authorization to reside and work because of exceptional circumstances at the time of filing the complaint. Other strategies enacted include the Strategic Plan for Citizenship and Integration (2007-2010) and the Plan for Prevention and Treatment of Gender-Based Violence Among the Immigrant Foreign Population (2009-2012). As has been reported in other countries (World Health Organization, 2010), most of these measures focus on eliminating barriers to accessing formal support, such as those related to women's legal (or illegal) immigrant status and language skills.

The political efforts described earlier can be supported by further scientific contributions concerning the experiences of and responses to IPV among different groups of immigrant women. In Spain, Ecuadorian, Moroccan, and Romanian women represent three of the main groups of immigrant women. These groups arrived in Spain during different periods: Moroccan immigration became substantial in the 1990s, most Ecuadorians arrived between 1999 and 2005, and Romanians have been entitled to residence since Romania joined the European Union in 2007. Most of the women from these immigrant groups belong to the class of unskilled manual laborers because they usually work in agriculture, domestic service, or tourism and as paid caregivers: Romanians (78.1\%), Moroccans (70.5\%), and Ecuadorians (67.1\%). Ecuadorian and Romanian women experience fewer linguistic barriers than Moroccan women. In terms of religion, Ecuadorian women are most similar to their Spanish counterparts because they are predominantly Catholic, whereas Moroccan and Romanian women are primarily followers of the Muslim and Orthodox religions, respectively (Fundación Encuentro, 2011). IPV research is still scant in the case of all three of these groups of women, both as immigrants and in their home countries (Gómez \& Speizer, 2009; United Nations Population Fund, 2007).

The main purpose of this study was to identify types of responses and help-seeking behavior among Moroccan, Romanian, and Ecuadorian women currently experiencing IPV in Spain. A further aim was to determine the most significant factors associated with the women's decision to seek help through not only informal resources but also formal IPV-related resources available (professionals, services).

\section{METHOD}

\section{Data Source}

This study used data from a cross-sectional study of immigrant women residing in municipalities in the provinces of Madrid, Valencia, and Barcelona in 2011. The study population included Ecuadorian, Moroccan, and Romanian immigrant women because, according to data from the National Statistics Institute in 2012, these groups of women accounted for $20 \%$ of all female immigrants in Spain. We employed an opportunistic selection strategy to select participants, establishing a fixed quota of 535 participants per country of origin and residential area to be able to conduct a comparison between the different groups of women. The geographical distribution of these target subsamples was determined according to the distribution of the corresponding immigrant female population aged older than 20 years obtained from the Spanish National Statistics Institute. A multistage clustering 
scheme was applied. The first stage of sample stratification was by province, in proportion to the population weight of each group. In the second stage, the sample was distributed within each province according to the size of the population in cities and municipalities (noncapital city $<50,000$ inhabitants, noncapital $>50,000$ inhabitants, and capital city). In the third stage, the sample was assigned to municipalities according to the following conditions: (a) that the total number of selected municipalities would represent at least $50 \%$ of the weight of the universe of each group of immigrant women studied and (b) that at least seven interviews would be held in each municipality. If any of the initially selected municipalities did not meet the second condition (e.g., if four rather than seven interviews were assigned to one of the selected municipalities) because of having a low proportion of resident Moroccan, Romanian, and/or Ecuadorian women, it was eliminated and the questionnaires that had been assigned to that municipality were distributed to other municipalities that did comply with this requirement. Once the entire sample had been assigned, we confirmed that Condition 1 was fulfilled in all three provinces.

Fieldwork was conducted between November 2011 and January 2012. Interviewers sought potential participants in the street, taking random routes between 11 a.m. and 9 p.m. These routes were designed to pass through places where the highest concentrations of these women would be found, such as schools, parks, consulates and immigration offices, shopping centers, and transport nodes, according to information provided both by public service and nongovernmental organization (NGO) professionals. The interviewers and research team added other places to the final list. As a safety measure, the research team decided not to conduct interviews in interviewees' homes, but rather to try to find potential participants in the street. Interviewers were selected from the same country of origin or were people who spoke the same language as the interviewees to establish a closer relationship with the women concerned.

\section{Participant Recruitment and Data Collection}

Women were considered eligible to participate in this study if their country of origin was Ecuador, Morocco, or Romania; they had been resident in the municipalities selected for the sample for at least 1 year; and they had reported having a relationship in the past year. Women were excluded from the study if they did not speak or write Spanish or had cognitive problems that would prevent their participation in the study. Interviews were only conducted with women who were unaccompanied at the time of the interview. A total of 1,607 completed interviews were conducted.

Interviewers initially approached potential participants by explaining to that their contribution was needed in a study about women's health and well-being. Then they explained the main purpose of the study and the procedure (two types of questionnaires, questions about important women's health problems and factors related to their well-being, including those related to their family and intimate partner relationships).

Almost a third of the immigrant women targeted by the interviewers $(1,240$ of 3,940) were excluded from the study because they did not meet the inclusion criteria (partner, language, age, length of residence in Spain). In addition, 1,078 women refused to participate or abandoned the interview and 24 questionnaires were eliminated during the data-refinement stage. In total, 1,607 questionnaires were completed. A response rate of 59.3\% was obtained based on the American Association for Public Opinion Research standard definition for response rate, Type 2 (American Association for Public Opinion Research, 2008). 
To collect the required information, we used a two-part questionnaire. The first part contained questions about sociodemographic characteristics, social support, immigration process, and status and health status and was administered by the interviewers. The second part of the questionnaire was self-administered by interviewees because we considered it more appropriate to respect their privacy when answering the questions about exposure to and response strategies in situations of abuse.

The study population consisted of women reporting physical, sexual, and/or psychological IPV by a current or former intimate partner. This was measured through women's answers to the following questions: (a) Have you ever been physically abused (hit, slapped, kicked or pushed, etc.) by your current/former intimate partner since you've been living in Spain? (b) Have you ever been psychologically abused (threatened, insulted, humiliated, scared, etc.)? and/or (c) Have you ever been sexually abused (forced to engage in sexual activities against your will)? The response options for each of these questions were "never", "sometimes," or "many times." Cases of IPV were identified among women who reported having experienced one or more these types of IPV "sometimes" or "many times." These three questions were used in previous studies conducted by some of the authors, showing high levels of comprehension and acceptability among immigrant and nonimmigrant women in Spain (Montero et al., 2012). We obtained 194 women who reported experiencing an IPV situation.

\section{Independent Variables}

Women's Characteristics. Country of origin (Morocco, Romania, or Ecuador), length of stay in Spain ( $\leq 10$ years, $>10$ years), age (18-40 years, $>40$ ), educational level (no formal or primary educational level, secondary or university education), dependents — having children and/or other dependent relatives in Spain or their country of origin (yes, no), level of religious involvement ("low" in the case of women who considered that they were not or not very religious and "high" in the case of women who considered themselves to be very or fairly religious), and partner's country of origin (born in Spain, born in another country). In addition, we included women's current labor status (employed or unemployed). We asked women about their current labor status and the response alternatives were as follows: housewife, employed or with a paid job, unemployed, and others (students, retired). We considered "employed or with a paid job" those women who reported this labor status and "unemployed or without a paid job" those who chose the other alternatives (unemployed, housewives, and others).

Intimate Partner Violence Severity. A compound index of IPV severity was used (29) in this study, based on the sum of scores for the following dimensions: (a) 1 point if women reported having been physically abused during their intimate relationship "sometimes," (b) 1 point if they reported having been psychologically abused "sometimes," (c) 1 point if they reported having been sexually abused "sometimes," (d) 2 points if they reported having been physically abused during their intimate relationship "many times", (e) 2 points if they reported having been psychologically abused "many times", (f) 2 Two points if they reported having been sexually abused "many times," (g) 1 point if women declared that the duration of these IPV situations was between 1 and 3 years, (h) 2 when IPV duration was between 4 and 8 years, and (i) 3 points when IPV duration was 9 years or more. The resulting scores of the composite index of IPV severity were from 1 to 9. Two levels were identified through a K-means analysis (Jain, 2010): low-severity IPV for scores from 1 to 4 and high-severity IPV for those between 5 and 9. 
Vives-Cases and La Parra

\section{Outcome Variables}

Three outcome IPV response-related variables were considered in this study: (a) responses in an IPV situation, (b) informal help-seeking or seeking help through different informal channels, and (c) formal help-seeking or seeking help through different formal channels.

1. Responses in an IPV situation: Women were asked "Have you ever tried to resolve your IPV situation since you've been living in Spain?" and the mutually exclusive response options were as follows: (a) I have not tried to resolve the situation, (b) I would like to resolve the situation but do not know how, and (c) Yes, I have tried to resolve the situation. Women's responses were coded as positive (Yes) if they chose option "c" and as negative (No) if they chose "a" or "b".

2. Formal versus informal help-seeking: The women were presented with a list of several avenues that they might have explored to try to resolve their situation of IPV since they had arrived in Spain. For each alternative, they were asked to indicate whether they had never, sometimes, or often attempted to use it. The alternatives were as follows: (a) I have tried to resolve the situation by talking with my partner, (b) I have asked my family for advice, (c) I have asked my partner's family for advice, (d) I have asked a friend for advice, (e) I have asked my spiritual counsellor for advice (f) I have asked a work colleague for advice, (g) I have been to a women's association or center, (h) I have sought assistance from health care professionals (doctor, nurse, psychologist, or social worker at my health center), (i) I have sought assistance from social care professionals (psychologist, social worker, welfare officer, social mediator, social educator), (j) I have asked a lawyer for advice, and (k) I have filed a complaint against my partner with the police. None of these 11 possible responses were mutually exclusive. The research team adapted these answer alternatives from a previous study that was also performed in Spain with immigrant and native women (Montero et al., 2012).

Women's responses were coded as informal help-seeking behavior if they sought help from their own family, from their partner's family, their friends, a spiritual counsellor and/or colleague, and/or tried to solve the situation by talking with their partners (Alternatives 1-6).

Women's responses were coded as formal help-seeking behavior if they sought help from a women's association and/or IPV-related services, health care and/or social care professionals, and lawyers, and/or reported their partner to the police (Alternatives 7-11).

\section{Statistical Analyses}

A descriptive study was conducted based on frequencies and percentages of both explanatory and outcome variables. We also used chi-squared tests $(p<.005)$ to compare the characteristics of the different groups of immigrant women studied. Bivariate and multivariate logistic regression analyses were fitted to calculate crude and adjusted associations with both informal and formal help-seeking behaviors. Women who reported seeking help only through informal channels were considered as the reference group. Women's characteristics and IPV severity levels were used first as control and then as explanatory variables. All variables were potential confounders of the primary exposure variable, and therefore they were all were included in the model. The logistic regression showed the model to be a very good fit. This was evidenced by the high Nagelkerke $R^{2}(0,227)$ and the results of the Hosmer-Lemeshow test for goodness of fit ( $p$ value $=.503$ ). Despite the reduced sample size, we calculated $95 \%$ confidence intervals (CI) to give an indication of the accuracy of the estimated odds ratios. Missing data were handled by pairwise deletion. All analyses were conducted using SPSS statistical software Version 15.0. 


\section{Ethical Considerations}

Informed verbal consent was obtained from all participants prior to beginning the interview. All participants were given written information on local and national Violence Against Women (VAW) help lines at the end of the interview. We followed the Recommendations on Ethics and Safety in research on gender-based VAW in the design, interviewer training, data collection, and interaction with women who participated in the study (Ellsberg \& Heise, 2002). The study was approved by the Ethics Committee of the University of Alicante. The interviewers ensured that an atmosphere of safety and trust prevailed during fieldwork because some of the interviewees stated that they either were or had been in an abusive situation. The interviewers were well informed regarding listening to and informing the women in question. At the end of the interview, all women were given written information on local and national VAW help lines, which would be able to provide further information on existing health, legal, and social services and educational resources in the community. The interviews were not always conducted in the same place as where the women had been recruited. Sometimes, it was necessary to conduct the interview elsewhere (in a cafe, waiting room of an NGO or a different setting which was specifically prepared by the research team if it was available, or their own homes if women preferred this option, after ensuring that nobody else was home) to provide the participant with more privacy and peace of mind. If another person appeared during an interview, such as someone who appeared to be her partner, the interview was abandoned. Interviewers were asked to leave at least 10 min between each interview to avoid including women in the study who might have been nearby or had overheard part of the last interview conducted with a previous woman.

\section{RESULTS}

There are $72.6 \%(n=141)$ of the 194 IPV cases identified in this study who answered questions related to their help-seeking behavior. These women's characteristics are described in Table 1. We observed statistically significant differences between the groups of immigrant women studied in terms of the characteristics related to length of residence, employment, religious involvement, and country of origin of the couple. Most Moroccan and Ecuadorian women had lived in Spain for 10 years or more, whereas just more than $80 \%$ of the Romanian women had immigrated to Spain less than 10 years ago. Most Romanian and Ecuadorian women reported that they were working, whereas $77.8 \%$ of the Moroccan women indicated that they were unemployed. The percentage of Moroccan women who reported a high level of religious involvement (77.8\%) was markedly higher than for the other groups. Lastly, a much higher percentage of Romanian women reported having Spanish partners (16.1\%), whereas no cases were recorded among the Moroccan women and barely $4 \%$ of Ecuadorian women had Spanish partners.

The most frequent situation among all the groups of women was overlapping types of abuse (principally physical and psychological abuse). An IPV situation of 9 years or more in duration was reported by $55 \%$ of Romanian women, $47 \%$ of Ecuadorians, and $46 \%$ of Moroccans. Cases of high IPV severity were most frequent among the Moroccan women $(55.6 \%)$ but were also very frequent among women from Romania (46.8\%) and Ecuador (44.2\%, Table 2).

There are $84 \%$ of women who reported seeking help through either informal and/ or formal channels. Informal help-seeking was more frequent $(84.4 \%)$ than formal 
TABLE 1. Characteristics of Moroccan, Ecuadorian, and Romanian Women Reporting Intimate Partner Violence in Spain (2011)

\begin{tabular}{|c|c|c|c|c|}
\hline \multirow[b]{2}{*}{ Characteristics } & & \multirow{2}{*}{$\frac{\text { Moroccans }}{n=27}$} & \multirow{2}{*}{$\begin{array}{c}\text { Ecuadorians } \\
n=52\end{array}$} & \multirow{2}{*}{$\frac{\text { Romanians }}{n=62}$} \\
\hline & & & & \\
\hline \multirow{2}{*}{$\begin{array}{l}\text { Years living } \\
\text { in Spain }\end{array}$} & $\leq 10$ & $13(48.1)$ & $20(38.5)$ & $50(80.6)^{* *}$ \\
\hline & $>10$ & $14(51.9)$ & $32(61.5)$ & $12(19.4)$ \\
\hline \multirow[t]{2}{*}{ Age (years) } & $18-40$ & $22(81.5)$ & $34(65.4)$ & 39 (62.9) \\
\hline & $>40$ & $5(18.5)$ & $18(34.6)$ & $23(37.1)$ \\
\hline \multirow[t]{2}{*}{ Education } & $\begin{array}{l}\text { No formal or only } \\
\text { primary education }\end{array}$ & $10(37.0)$ & $8(15.4)$ & $12(19.4)$ \\
\hline & $\begin{array}{l}\text { Secondary or university } \\
\text { education }\end{array}$ & $17(63.0)$ & $44(84.6)$ & $50(80.6)$ \\
\hline \multirow[t]{2}{*}{ Employed } & Yes & $6(22.2)$ & $43(82.7)$ & $49(79.0)^{* *}$ \\
\hline & No & $21(77.8)$ & $9(17.3)$ & $13(21.0)$ \\
\hline \multirow[t]{2}{*}{ Dependents } & Yes & $22(81.5)$ & $49(94.2)$ & $55(88.7)$ \\
\hline & No & $5(18.5)$ & $3(5.8)$ & 7 (11.3) \\
\hline \multirow{2}{*}{$\begin{array}{l}\text { Religious } \\
\text { involvement }\end{array}$} & High & $21(77.8)$ & $26(50.0)$ & $31(50.0)^{*}$ \\
\hline & Low & $6(22.2)$ & $26(50.0)$ & $31(50.0)$ \\
\hline \multirow{2}{*}{$\begin{array}{l}\text { Partner was } \\
\text { born in Spain }\end{array}$} & Yes & $0(0.0)$ & $2(3.8)$ & $10(16.1)^{* *}$ \\
\hline & No & $27(100.0)$ & $50(96.2)$ & $52(83.9)$ \\
\hline
\end{tabular}

$* p<.05 . * * p<.001$ according to chi-squared test.

TABLE 2. Intimate Partner Violence (IPV) Characteristics Among Moroccan, Ecuadorian, and Romanian Women Living in Spain (2011)

\begin{tabular}{|c|c|c|c|c|}
\hline \multirow[b]{2}{*}{ Characteristics } & & \multirow{2}{*}{$\frac{\text { Moroccans }}{n=27}$} & \multirow{2}{*}{$\frac{\text { Ecuadorians }}{n=52}$} & \multirow{2}{*}{$\begin{array}{c}\text { Romanians } \\
n=62\end{array}$} \\
\hline & & & & \\
\hline \multirow[t]{4}{*}{ Types of abuse } & Solely physical & $0(0.0)$ & $8(15.4)$ & $5(8.1)$ \\
\hline & Solely psychological & $8(29.6)$ & $3(5.8)$ & $13(21.0)$ \\
\hline & Solely sexual & $2(7.4)$ & $0(0.0)$ & $0(0.0)$ \\
\hline & $\begin{array}{l}\text { Overlapping types } \\
\text { of abuse }\end{array}$ & $17(63.0)$ & $41(78.8)$ & $44(71.0)$ \\
\hline \multirow[t]{2}{*}{ Duration of IPV } & $<9$ years & $14(53.8)$ & $27(52.9)$ & $27(45.0)$ \\
\hline & $\geq 9$ years & $12(46.2)$ & $24(47.1)$ & $33(55.0)$ \\
\hline \multirow[t]{2}{*}{ Severity IPV } & Low (1-4) & $12(44.4)$ & $29(55.8)$ & $33(53.2)$ \\
\hline & $\operatorname{High}(5-9)$ & 15 (55.6) & $23(44.2)$ & $29(46.8)$ \\
\hline
\end{tabular}

AQ7 ${ }^{*} p<.05 .{ }^{*} p p<.001$ according to chi-squared test. 
help-seeking (44.7\%). It should be noted, however, that $100 \%$ of the women who reported seeking help through formal channels also reported having sought help through informal ones. As shown by the figures presented in Table 3, talking to the partner was the most common informal help-seeking behavior among Moroccan (63\%), Romanian (83.9\%), and Ecuadorian (80.8\%) women. Regarding formal help-seeking behavior, Moroccans identified social services (29.6\%) and health care professionals $(25.9 \%)$ as the resources they turned to most frequently when seeking this type of help. Approximately $32 \%$ of Ecuadorians and Romanians declared having reported their partners to police, whereas

TABLE 3. Help-Seeking Behavior Among Moroccan, Ecuadorian, and Romanian Women Reporting Intimate Partner Violence in Spain (2011)

\begin{tabular}{|c|c|c|c|}
\hline \multirow[b]{2}{*}{ Formal Help-Seeking } & \multicolumn{3}{|c|}{ Usage Frequency } \\
\hline & $\begin{array}{l}\text { Moroccans } \\
n(\%)\end{array}$ & $\begin{array}{c}\text { Ecuadorians } \\
n(\%)\end{array}$ & $\begin{array}{l}\text { Romanians } \\
n(\%)\end{array}$ \\
\hline \multicolumn{4}{|c|}{ Seeking help through any type of formal channel } \\
\hline $\begin{array}{l}\text { I have sought help from services } \\
\text { for battered women. }\end{array}$ & $3(11.1)$ & $11(21.2)$ & $5(8.1)$ \\
\hline $\begin{array}{l}\text { I have sought help from social } \\
\text { services professionals. }\end{array}$ & 8 (29.6) & $14(26.9)$ & $12(19.4)$ \\
\hline $\begin{array}{l}\text { I have sought help from health care } \\
\text { professionals. }\end{array}$ & $7(25.9)$ & $13(25.0)$ & $10(16.1)$ \\
\hline I have sought help from a lawyer. & $5(18.5)$ & $10(19.2)$ & $22(35.5)$ \\
\hline $\begin{array}{l}\text { I have reported my partner to the } \\
\text { police. }\end{array}$ & $5(18.5)$ & $17(32.7)$ & $20(32.3)$ \\
\hline $\begin{array}{l}\text { Women who reported at least one } \\
\text { formal source }\end{array}$ & $10(37.0)$ & $26(50.0)$ & $27(43.5)$ \\
\hline \multicolumn{4}{|l|}{ Informal Help-Seeking } \\
\hline \multicolumn{4}{|c|}{ Seeking help through any type of informal channel } \\
\hline I have tried talking with my partner. & $17(63.0)$ & $42(80.8)$ & $52(83.9)$ \\
\hline $\begin{array}{l}\text { I have sought advice from my } \\
\text { family. }\end{array}$ & $10(37.0)$ & $32(61.5)$ & $43(69.4)$ \\
\hline $\begin{array}{l}\text { I have sought advice from my } \\
\text { partner's family. }\end{array}$ & $8(29.6)$ & $19(36.5)$ & $29(46.8)$ \\
\hline I have sought help from a friend. & $10(37.0)$ & $38(73.1)$ & $33(53.2)$ \\
\hline $\begin{array}{l}\text { I have sought advice from my } \\
\text { spiritual counselor. }\end{array}$ & $10(37.0)$ & $23(44.2)$ & $21(33.9)$ \\
\hline $\begin{array}{l}\text { I have sought help from a colleague } \\
\text { at my workplace. }\end{array}$ & $4(14.8)$ & $15(28.8)$ & $18(29.0)$ \\
\hline $\begin{array}{l}\text { Women who reported at least one } \\
\text { informal source. }\end{array}$ & $17(63.0)$ & $46(88.5)$ & $56(90.3)$ \\
\hline
\end{tabular}


TABLE 4. Multivariate Logistic Regression Analysis of Factors Associated With Formal Help-Seeking Behavior Versus Informal Help-Seeking Only, Among Immigrant Women Reporting Intimate Partner Violence (IPV) in Spain (2011)

\begin{tabular}{|c|c|c|c|}
\hline & \multirow[b]{2}{*}{$\begin{array}{l}\text { Crude } O R \\
\text { (CI 95\%) }\end{array}$} & \multirow{2}{*}{ 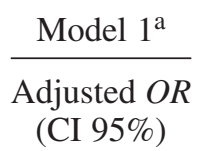 } & \multirow{2}{*}{$\frac{\text { Model } 2^{\mathrm{b}}}{\text { Adjusted } O R}$} \\
\hline & & & \\
\hline $\begin{array}{l}\text { Nonrecent immigrant } \\
(10 \text { years or more }) \\
\text { versus recent } \\
\text { immigrant }(<10 \text { years })\end{array}$ & $\begin{array}{c}0.85 \\
{[0.41,1.79]}\end{array}$ & $\begin{array}{c}0.99 \\
{[0.44,2.24]}\end{array}$ & $\begin{array}{c}1.02 \\
{[0.41,2.55]}\end{array}$ \\
\hline $\begin{array}{l}\text { Younger }(\leq 40) \text { versus } \\
\text { older }(>40)\end{array}$ & $\begin{array}{c}0.72 \\
{[0.34,1.53]}\end{array}$ & $\begin{array}{c}0.74 \\
{[0.35,1.58]}\end{array}$ & $\begin{array}{c}0.38 \\
{[0.15,0.95]}\end{array}$ \\
\hline $\begin{array}{l}\text { Employed versus } \\
\text { unemployed }\end{array}$ & $\begin{array}{c}0.72 \\
{[0.32,1.60]}\end{array}$ & $\begin{array}{c}0.57 \\
{[0.22,1.45]}\end{array}$ & $\begin{array}{c}0.40 \\
{[0.14,1.19]}\end{array}$ \\
\hline $\begin{array}{l}\text { Childless women } \\
\text { versus women with } \\
\text { children and/or other } \\
\text { dependents }\end{array}$ & $\begin{array}{c}1.39 \\
{[0.40,4.84]}\end{array}$ & $\begin{array}{c}1.43 \\
{[0.41,5.06]}\end{array}$ & $\begin{array}{c}0.69 \\
{[0.16,2.94]}\end{array}$ \\
\hline $\begin{array}{l}\text { Religious involvement } \\
\text { High versus low }\end{array}$ & $\begin{array}{c}1.62 \\
{[0.78,3.37]}\end{array}$ & $\begin{array}{c}1.61 \\
{[0.76,3.41]}\end{array}$ & $\begin{array}{c}1.16 \\
{[0.48,2.79]}\end{array}$ \\
\hline $\begin{array}{l}\text { Partner born } \\
\text { Spain versus other }\end{array}$ & $\begin{array}{c}2.94 \\
{[0.76,11.48]}\end{array}$ & $\begin{array}{c}3.73 \\
{[0.92,15.22]}\end{array}$ & $\begin{array}{c}3.88 \\
{[0.87,17.26]}\end{array}$ \\
\hline $\begin{array}{l}\text { Severity IPV } \\
\text { High versus low }\end{array}$ & $\begin{array}{c}3.99 \\
{[1.85,8.59]}\end{array}$ & $\begin{array}{c}4.14 \\
{[1.90,9.02]}\end{array}$ & $\begin{array}{c}5.69 \\
{[2.29,14.12]}\end{array}$ \\
\hline
\end{tabular}

Note. $O R=$ odds ratio; $\mathrm{CI}=$ confidence interval.

${ }^{a}$ Model 1: adjusted only by country of origin.

bModel 2: adjusted by country and all violence and women's characteristics.

$18,5 \%$ of Moroccan reported their partners. In addition, a considerable number of Romanian women also reported having sought help from lawyers (35.5\%). Between 50\% and $37 \%$ of these women reported having sought help from at least one type of formal resource, whereas $63 \%-90 \%$ reported having sought at least one type of informal source of help in IPV situations.

According to the results shown in Table 4, the likelihood of seeking help through informal and formal channels versus informal channels alone was higher in cases of high IPV severity than in lower levels of IPV severity, even after adjusting for the effects of other factors (adjusted odds ratio $[a O R]=5.69$, CI 95\% [2.29, 14.12]; Table 4).

\section{DISCUSSION}

One of the main results of this study is that most of the women affected reported that they had tried to find a solution to their IPV situation through seeking help from either formal and/or informal resources. Although all of the women who reported having sought help 
made use of one or several of the informal resource options analyzed, only half of them made use of the formal resources available in Spain. The likelihood of seeking help from not only informal but also formal resources is associated with greater severity of abuse. When interpreting these findings, it is important to keep in mind the effect of the multiple barriers to access to formal resources that immigrant women face, especially those who have recently arrived (Ahmad et al., 2009; Brabeck \& Guzmán, 2008; Crandall et al., 2005; Dutton et al., 2000; Hyman et al., 2006; Ting, 2010).

The Moroccan, Romanian, and Ecuadorian women who participated in our study tended to respond actively to IPV. However, the most frequently used resource cited by all three groups of women was that of attempting to find a solution to the situation by talking to the partner. Although it is not clear whether this resource provides a true source of help, this is one of the most frequent first steps that women take when initiating help-seeking processes (Liang, Goodman, Tummala-Narra, \& Weintraub, 2005). Apart from talking to the partner, there were higher rates of help-seeking for the informal resources (family, friends, spiritual counselors, and coworkers) than for the formal ones. Thus, increasing community awareness of IPV and the need to address it is crucial (Hyman et al., 2006).

Whereas $72 \%$ of Spanish women usually seek formal help (Montero et al., 2012), the percentage is much lower for the groups of immigrant women studied. In accordance with previous studies (Barrett \& St. Pierre, 2011; Djikanović et al., 2012; Hyman et al., 2006; Kiss et al., 2012), the likelihood of seeking help through this type of resource only increases when the severity of the abuse also increases. These results suggest the need for institutional strategies to eliminate barriers to access for the immigrant population. It is important to address the lack of culturally appropriate IPV services in Spain, improve coordination among all relevant institutions, and/or increase sources of information for immigrant women (Briones-Vozmediano, La Parra, \& Vives-Cases, 2014; Guruge \& Humphreys, 2009; Lee \& Hadeed, 2009).

Regarding possible differences between the groups of immigrant women studied, the most relevant ones were observed by the type of formal resources reported. The Moroccan women tended to seek help more often from professionals working in nonspecific IPV services, such as health care professionals and social workers, whereas reporting the situation to the police was more frequent among Romanian and Ecuadorian women. Furthermore, a substantial percentage of Romanian women had sought help from a lawyer, a formal resource that is also frequently used by women in situations of IPV in other countries (Djikanović et al., 2012). Particularly striking was the small number of women who approached services specifically aimed at women in an IPV situation. This highlights the relevance of taking a "comprehensive approach" to IPV among female immigrants, involving the participation of different services and professionals in the care of the women affected (United Nations, 2010).

\section{Limitations}

The cross-sectional design of this study prevented the assessment of causality in the observed relationships. The exclusion criteria used (illiterate women, those who were accompanied by a partner, and/or who did not understand Spanish) probably led to an underestimation of the prevalence of IPV detected. However, the fact that the nationalities studied present low levels of illegal immigrant status after 2005 (Fundación Encuentro, 2011) may have led to overestimation of the observed prevalence of helpseeking behavior from formal sources among the groups of women studied. In this study, 
we asked participants only about the experiences of IPV that they have suffered in Spain. Knowledge of the fact that past victimizations can affect present help-seeking behavior is also helpful to understanding the results and the differences between women. The results that refer to IPV characteristics and responses should be treated with caution given the low sample size of each of the groups of immigrant women. It should be borne in mind that response to these questions required women to acknowledge being in a situation of IPV, and this may have influenced the response rate obtained. Furthermore, the IPV measure used asks women if they have ever been physically abused, psychologically abused, and sexually abused. These are potentially value-laden terms that may make some women underreport their experiences of abuse because they may not believe that their experiences were "abuse" or they may not want to be labeled as being "abused." In this sense, it is especially important to explore whether women have ever been sexually abused and the use of the term forced. This term could be interpreted by some women as referring only to those acts including physical violence. Because of these limitations, the results of this study should be interpreted with caution and should not be generalized to these immigrant communities living in Spain.

\section{CONCLUSION}

It can be concluded that the most common response to IPV among immigrant women in Spain is to seek help, although women were more likely to seek help from informal than formal resources. As has been observed among nonimmigrant women, the likelihood of seeking help through professionals and services increases as the abuse becomes more severe. Greater efforts should be made to increase professionals' opportunities to intervene in cases of IPV before they become severe. In this sense, tackling the barriers faced by immigrant women in access to care and services is a vital first step.

\section{REFERENCES}

Ahmad, F., Driver, N., McNally, M. J., \& Stewart, D. E. (2009). "Why doesn't she seek help for partner abuse?" An exploratory study with South Asian immigrant women. Social Science and Medicine, 69(4), 613-622.

Amanor-Boadu, Y., Messing, J., Stith, S., Anderson, J., O’Sullivan, C., \& Campbell, J. (2012). Immigrant and nonimmigrant women: Factors that predict leaving and abusive relationship. Violence Against Women, 18(5), 611-633.

American Association for Public Opinion Research. (2008). Standard definitions: Final dispositions of case codes and outcome rates for surveys. Lenexa, KS: Author.

Ammar, N., Couture-Carron, A., Alvi, S., \& San Antonio, J. (2013). Experiences of Muslim and nonMuslim battered immigrant women with the police in the United States: A closer understanding of commonalities and differences. Violence Against Women, 19(12), 1449-1471.

Anderson, D. K., \& Saunders, D. G. (2003). Leaving an abusive partner: An empirical review of predictors, the process of leaving, and psychological well-being. Trauma, Violence, \& Abuse, 4(2), 163-191.

Barnett, O. W. (2001). Why battered women do not leave, Part 2. Trauma, Violence, \& Abuse, 2(1), 3-35.

Barrett, B., \& St. Pierre, M. (2011). Variations in women's help seeking in response to intimate partner violence: Findings from a Canadian population-based study. Violence Against Women, 17(1), 47-70. 
Brabeck \& Guzmán. (2008).

Briones-Vozmediano, E., La Parra, D., \& Vives-Cases, C. (2014). Barriers and facilitators to effective coverage of intimate partner violence services for immigrant women in Spain. Health Expectations, 18(6), 2994-3006.

Crandall, M., Senturia, K., Sullivan, M., \& Shiu-Thornton, S. (2005). "No way out": Russianspeaking Women's experiences with domestic violence. Journal of Interpersonal Violence, 20(8), 941-958.

Denham, A. C., Frasier, P. Y., Hooten, E. G., Belton, L., Newton, W., Gonzalez, P., . . Campbell, M. K. (2007). Intimate partner violence among Latinas in eastern North Carolina. Violence Against Women, 13(2), 123-140.

Djikanović, B., Wong, S., Jansen, H., Koso, S., Simić, S., Otasević, S., \& Lagro-Janssen, A. (2012). Help-seeking behaviour of Serbian women who experienced intimate partner violence. Family Practice, 29, 189-195.

Du mont, J., Hyman, I., O’Brien, K., White, M. E., Odette, F., \& Tyyskä, V. (2012). Factors associated with intimate partner violence by a former partner by immigration status and length of residence in Canada. Annals of Epidemiology, 22, 772-777.

Duterte, E. E., Bonomi, A. E., Kernic, M. A., Schiff, M. A., Thompson, R. S., \& Rivara, F. P. (2008). Correlates of medical and legal help seeking among women reporting intimate partner violence. Journal of Women's Health, 17(1), 85-95.

Dutton, M. A., Orloff, L. E., \& Hass, G. A. (2000). Characteristics of help-seeking behaviors, resources and service needs of battered immigrant Latinas: Legal and policy implications. Georgetown Journal on Poverty Law \& Policy, 7, 245-305.

Ellsberg, M., \& Heise, L. (2002). Bearing witness: Ethics in domestic violence research. Lancet, 359(9317), 1599-1604.

Fanslow, J. L., \& Robinson, E. M. (2010). Help-seeking behaviors and reasons for help seeking reported by a representative sample of women victims of intimate partner violence in New Zealand. Journal of Interpersonal Violence, 25(5), 929-951.

Flicker, S., Cerulli, C., Zhao, X., Tang, W., Watts, A., Xia, Y., \& Talbot, N. (2011). Concomitant forms of abuse and help-seeking behavior among White, African American, and Latina women who experience intimate partner violence. Violence Against Women, 17(8), 1067-1085.

Fundación Encuentro. (2011). Informe España 2011, una interpretación de su realidad social [Spain Report 2011, an interpretation of social reality]. Retrieved from http://www.fund-encuentro .org/informe_espana/indiceinforme.php?id=IE18

Gómez, A., \& Speizer, I. (2009). Intersections between childhood abuse and adult intimate partner violence among Ecuadorian women. Maternal and Child Health Journal, 13(4), $559-566$

Gondolf, E. W., \& Fisher, E. R. (1988). Battered women as survivors: An alternative to treating learned helplessness. Lexington, MA: Lexington Books.

Guruge, S., \& Humphreys, J. (2009). Barriers affecting access to and use of formal social supports among abused immigrant women. Canadian Journal of Nursing Research, 41(3), 64-84.

Hyman, I., Forte, T., Du Mont, J., Romans, S., \& Cohen, M. (2006). Help seeking rates for intimate partner violence among Canadian immigrant women. Health Care for Women International, 27, 682-694.

Hyman, I., Mason, R., Guruge, S., Berman, H., Kanagaratnam, P., \& Manuel, L. (2011). Perceptions of factors contributing to intimate partner violence among Sri Lankan Tamil immigrant women in Canada. Health Care for Women International, 32(9), 779-794.

Jain, A. K. (2010). Data clustering: 50 Years beyond K-means. Pattern Recognition Letters, 31(8), 651-666.

Jayasuriya, V., Wijewardena, K., \& Axemo, P. (2011). Intimate partner violence against women in the capital province of Sri Lanka: Prevalence, risk factors and help seeking. Violence Against Women, 17, 1086-1102. 
Kiss, L., Lucas, A., Zimmerman, C., Heise, L., Schraiber, L., \& Watts, C. (2012). Brazilian policy responses to violence against women: Government strategy and the help-seeking behaviours of women who experience violence. Health and Human Rights, 14, 1-14.

Koepsell, J. K., Kernic, M. A., \& Holt, V. L. (2006). Factors that influence battered women to leave their abusive relationships. Violence and Victims, 21(2), 131-147.

Lee, Y.-S., \& Hadeed, L. (2009). Intimate partner violence among Asian immigrant communities: Health/mental health consequences, help-seeking behaviors, and service utilization. Trauma, Violence, \& Abuse, 10(2), 143-170.

Liang, B., Goodman, L., Tummala-Narra, P., \& Weintraub, S. (2005). A theoretical framework for understanding help-seeking processes among survivors of intimate partner violence. American Journal of Community Psychology, 36(1), 71-84.

Linos, N., Slopen, N., Berkman, L., Subramanian, S., \& Kawachi, I. (2014). Predictors of helpseeking behaviour among women exposed to violence in Nigeria: A multilevel analysis to evaluate the impact of contextual and individual factors. Journal of Epidemiology and Community Health, 68(3), 211-217.

Lown, E. A., \& Vega, W. A. (2001). Prevalence and predictors of physical partner abuse among Mexican American women. American Journal of Public Health, 91(3), 441-445.

Montero, I., Ruiz-Pérez, I., Escribà-Agüir, V., Vives-Cases, C., Plazaola-Castaño, J., Talavera, M., . . . Peiró, R. (2012). Strategic responses to intimate partner violence against women in Spain: A national study in primary care. Journal of Epidemiology and Community Health, 66, 352-358.

Morrison, K., Luchok, K., Richter, D., \& Parra-Medina, D. (2006). Factors influencing help-seeking from informal networks among African American victims of intimate partner violence. Journal of Interpersonal Violence, 21, 1493-1511.

Naved, R., Azim, S., Bhuiya, A., \& Persson, L. (2006). Physical violence by husbands: Magnitude, disclosure and help-seeking behavior of women in Bangladesh. Social Science and Medicine, 62, 2917-2929.

Ponic, P., Varcoe, C., Davies, L., Ford-Gilboe, M., Wuest, J., \& Hammerton, J. (2011). Leaving $\neq$ moving housing patterns of women who have left an abusive partner. Violence Against Women, 17(12), 1576-1600.

Raj, A., \& Silverman, J. (2002). Violence against immigrant women. The roles of culture, context, and legal immigrant status on intimate partner violence. Violence Against Women, 8(3), 367-398.

Sagot, M. (2005). The critical path of women affected by family violence in Latin America: Case studies from 10 countries. Violence Against Women, 11(10), 1292-1318.

Shirwadkar, S. (2004). Canadian domestic violence policy and Indian immigrant women. Violence Against Women, 10(8), 860-879.

AQ5 Spanish Official Gazette. (2012). Royal Decree 1192/2012 of 3 August, which regulates the condition of the insured party and beneficiary for the purposes of publically funded health care in Spain provided through the Spanish National Health System. Retrieved from www.boe.es/boe/ dias/2012/08/04/pdfs/BOE-A-2012-10477.pdf

Ting, L. (2010). Out of Africa: Coping strategies of African immigrant women survivors of intimate partner violence. Health Care for Women International, 31(4), 345-364.

United Nations. (2010). Handbook for legislation on violence against women. New York, NY: Author.

United Nations Population Fund. (2007). Programming to address violence against women: Ten case studies. New York, NY: Author.

Vives-Cases, C., Álvarez-Dardet, C., Torrubiano-Domínguez, J., \& Gil-González, D. (2008). Mortality due to intimate partner violence in foreign women living in Spain (1999-2006). Gaceta Sanitaria, 22(3), 232-235.

Vives-Cases, C., Gil-González, D., Ruiz-Pérez, I., Escribà-Agüir, V., Plazaola-Castaño, J., MonteroPiñar, M. I., \& Torrubiano-Domínguez, J. (2010). Identifying sociodemographic differences in intimate partner violence among immigrant and native women in Spain: A cross-sectional study. Preventive Medicine, 51(1), 85-87. 
Vives-Cases, C., Torrubiano-Domínguez, J., Escribà-Agüir, V., Ruiz-Pérez, I., Montero-Piñar, M. I., \& Gil-González, D. (2011). Social determinants and health effects of low and high severity intimate partner violence. Annals of Epidemiology, 21(12), 907-913.

World Health Organization. (2010). Preventing intímate partner and sexual violence against women. Geneva, Switzerland: Author.

Acknowledgments. We want to thank all the women who voluntarily participated in this study, gave their time to complete the questionnaire, and shared their experiences of violence with us. Without them, this study would not have been possible. We want to thank the Carlos III Health Institute (Ministry of Science and Innovation, Spain) for financial support for the project "Intimate Partner Violence Among Immigrant Women in Spain: Prevalence, Risk Factors, and Determinants of Access to Social and Health Services" [PI10/00151].

Correspondence regarding this article should be directed to Carmen Vives-Cases, PhD, Department of Preventive Medicine and Public Health, Alicante University, Apto. 99, 03080 Alicante, Spain. E-mail: carmen.vives@ua.es 